\title{
INQUÉRITO SOROLÓGICO PARA O DIAGNÓSTICO DA DOENÇA DE CHAGAS ENTRE DOADORES DE UM BANCO DE SANGUE DO RECIFE.
}

\author{
Donald Huggins *:, Durval T. Lucena ***, Anacleto de Carvalho **** e Benjamim \\ Figueirêdo. $* * * * *$
}

Os autores, efetuando um inquérito sorológico baseado na reação de Guerreiro-Machado para o diagnóstico da doença de Chagas em 136 candidatos não selecionados a doadores do Banco de Sangue do Hospital das Clinicas da F.M.U.F.Pe., Brasil, encontraram seis $(4,41 \%)$ com reacões positivas.

A transfusão de sangue ou de seus derivados representa um valioso recurso terapêutico, muito embora diversas infecções possam ser transmitidas, tais como febre recurrente, sifilis, malária, hepatite por virus, febre tifóide, sarampo, toxoplasmose, variola, septicemias, brucelose, doença de Chagas etc. Em nosso meio, assume particular importância a doença de Chagas como infecção capaz de ser transmissivel pela transfusão de sangue. Sendo endêmica em várias áreas do Estado, com incidência relativamente alta, pode-se deduzir que a doenca de Chagas representa um grave problema médico e de Saúde Pública. Lucena (25), realizando um estudo epidemiológico, encontrou a seguinte distribuicão da parasitose (Tabela anexa)

Esta pesquisa veio demonstrar o grande perigo que correm os receptores de sangue em nossos hospitais, tanto do interior como da Capital, principalmente êstes últimos, pois para Recife tem afluido enorme contingente de individuos do interior do Estado em busca de melhores condições sócio-economicas e que poderão tornar-se doadores voluntários ou profissionais.
Por outro lado, sabemos que a maioria dos Bancos de Sangue não executam rigorosa triagem clínica e laboratorial nos candidatos a doadores de sangue; na verdade, as transfusões diretas representam perigoso veículo para inoculação de Trypanosoma cruzi, pois basta lembrarmos que geralmente nas transfusões injetam-se em média cêrca de 250 a $500 \mathrm{ml}$ de sangue enquanto os animais inoculados para fins de diagnóstico, ou mesmo triatomíneos, infectam-se fảcilmente com pequenas quantidades de sangue $(0,05$ a $1,0 \mathrm{ml})$. Sullivan 43) observou que o Trypanosoma cruzi pode manter-se viável e multiplicar-se no sangue citratado de cobaia infectado experimentalmente, mesmo mantido à temperatura ambiente durante 257 dias. Entretanto, o protozoário é capaz de ser destruído quando submetido a elevações moderadas da temperatura. Paprocki (34) notou a destruição em 3 horas das formas sanguicolas do Trypanosoma cruzi quando mantidas "in vitro" a $41-41,5^{\circ} \mathrm{C}$; ao contrário o Trypanosoma cruzi pode suportar temperaturas baixas de $6^{\circ} \mathrm{C}$ durante 21 dias $(30)$ ou de $-70^{\circ} \mathrm{C}$ durante 8 mêses (44), e no sangue centrifugado durante 15

\footnotetext{
(*) Instituto ae Medicina Tropical da F.M.L.F.Pe, Recife, Pernambuco, Brasil.

(**) Prof. Assistente do Instituto de Medicina Tropical.

(***) Prof. Adjunto de Parasitologia da F.M.L.F.Pe.

(***) Chefe do Banco de Sangue do Hospital das Clinieas da F.M.L.F.Pe.

(****) Acadêmico estagiário do Instituto de Medicina Tropical.

Recebido para publicacáo em 16-10-1969.
} 
T A B E L A

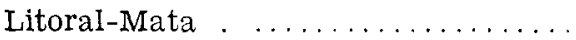

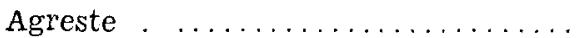

Sertão

Total

minutos a uma rotação de 3.000 por minuto. Donde conclui-se que a infecção chagásica representa um perigo potencial, podendo ser transmitida tanto por transfusão de sangue conservado à temperatura ambiente ou a baixas temperaturas $\left(-70^{\circ} \mathrm{C}\right)$, como também pela transfiusão dio
\end{abstract} plasma.

A presente investigação compreende os resultados de um inquérito sorológico efetuado com a reação de Guerreiro-Machado (22) para o diagnóstico da doença de Chagas entre cand datos a doadores de sangue do Banco de Sangue do Hospital das Clínicas da F.M.U.F.Pe., Brasil.

\section{MATERIAL E MÉTODOS}

O nosso material consta de 136 individuos não selecionados que se apresentaram como candidatos a doadores de sangue no Hospital das Clínicas da F.M.U.F.Pe. no período compreendido entre 13 de junho a 11 de novembro de 1968. Dêstes, 127 pertenciam ao sexo masculino e 9 ao feminino; todos aparentemente gozavam boa saúde durante o exame clínico. Realizamos 136 reações de Guerreiro-Machado para o diagnóstico da doença de Chagas segundo a técnica de Muniz \& Freitas (28), utilizando o antigeno metílico de Batista \& Ramos. Os soros eram geralmente conservados em geladeira $\left(4^{\circ} \mathrm{C}\right)$ até o momento do exame, freqüentemente realizado cêrca de três a cinco dias após a colheita do material.

\section{RESULTADOS}

A reação de fixação do complemento para o diagnóstico da doença de Chagas realizada em 136 candidatos a doadores de sangue fol positiva em $6(4,41 \%)$. (Quadro único). Cinco eram do sexo masculino o um do feminino e apenas um dêles compareceu para exame clínico, radiológico e parasitológico (xenodiagnóstico), não se encontrando nenhuma anormalidade, apesar de informar que já residiu em área

\begin{tabular}{|c|c|c|c|c|}
\hline 1.314 & exames & 192 & sitivos & $(14,6 \%)$ \\
\hline 1.544 & $"$ & 234 & $"$ & $(15,1 \%)$ \\
\hline 409 & " & 60 & $"$ & $(14,67 \%)$ \\
\hline 267 & " & 486 & " & $(14,8 \%$ \\
\hline
\end{tabular}

endêmica no Estado de Pernambuco (Catende) e que já foi sugacio por triatomíneos.

\section{COMENTÁRIOS}

Desde que Dias (15) chamou atenção para a possibilidade da transmissão da doença de Chagas pela transfusão de sangue, o problema vem sendo abordado em todos os seus ângulos por diversos pesquisadores. Pellegrino \& col (36) apresentaram os três primeiros casos da doença de Chagas comprovados sorologicamente pela reação de fixação do complemento em dois doadores e em um candidato a doador de sangue entre 179 doadores ou candidatos a doadores de sangue inscritos em Serviços de Transfusāo de Belo Horizonte. Dois casos eram assintomáticos e um apresentava cardiopatia chagásica crônica com bloqueio do ramo direito do feixe de His. Faria \& col. (16) verificaram no Banco de Sangue do Hospital Municipal de São Paulo cinco reacoóes positivas $(1 \%)$ em 500 doadores de sangue. Aconselharam como medidas profiláticas as seguintes normas: 1) - anamnese cuidadosa e exame clínico rigoroso nos doadores; 2) - realização sistemática da reacão de Guerreiro-Machado (22) em todos os doadores e 3) - aproveitamento dos sangues cujas reações foram positivas, sòmente após 10 dias de armazenamento em geladeira e sob a forma de plasma congelado. Posteriormente, Faria (17), realizando nova revisão estatística no Banco de Sangue do mesmo Hospital, verificou que dos 2.223 doadores so foi possivel realizar a reação de fixação do complemento para o diagnóstico da doença de Chagas em 92 , encontrando sete positivas $(7,6 \%)$. Os sangues foram conservados durante 10 dias a $4^{\circ} \mathrm{C}$ e após êste prazo, três sangues cujas reações foram positivas foram transfundidos a três pacientes e nenhum receptor manifestou qualquer sintoma ou sinal de doença de Chagas nos meses subsequen- 
tes e a reação de Guerreiro-Machado moštrou-se negativa em todos com intervalo de vários meses. Passalacqua \& col. (35), efetuando um inquérito sorológico por intermédio da R.F.C. para o diagnóstico da doença de Chagas em 536 candidatos a doadores do Banco de Sangue da Santa Casa de Misericórdia de São Paulo, encontraram $4,1 \%$ de reaçóes positivas (22 doadores).

Biancalana \& col. (8) através da R.F.C. para o diagnóstico da doença de Chagas executada em candidatos a doadores, não selecionados, nos Bancos de Sangue dos Hospitais São Francisco, de Ribeirão Prêto, Beneficência Poriuguêsa, Santa Casa de Misericórdia de Santos, Santa Casa de didatos a doadores de sangue aparentemente sadios. Não há, no entanto, especificação do número de indivíduos examinados. Castro \& Uvo (11), durante quinze meses fizeram o joeiramento sorológico para a moléstia de Chagas nos doadores do interior e da Capital de São Paulo que procuraran - Banco de Sangue do Hospital São Luís Gonzaga (Jaçanã, São Paulo). Nos 327 doadores residentes na Capital, oito $(2,4 \%)$ apresentaram reaçōes positivas, enquanto dos 300 provenientes do interior do Estado, cinco $(1,66 \%)$ apresentaram a reação de Guerreiro-Machado positiva. Amato Neto (3) relata que seis casos seguramente infectados pela transfusão de sangue. Todos os pacientes foram exaustivamente estu-

\section{QUADRO}

Ficzcão de Guerreiro-Machado entre doadores do Banco de Sangue do Hospital das Clínicas da F.M.U.F.Pe.

\begin{tabular}{|c|c|c|}
\hline N.o de doadores & Reações positivas & Percentual \\
\hline 136 & 6 & $4,41 \%$ \\
\hline
\end{tabular}

Misericórdia de São José do Rio Prêto e de Araguari, obtiveram taxas de positividade de $21 \%, 0 \%, 0 \%, 14,9 \%$ e de $19,1 \%$ em relação a $19,28,66,134$ e 225 candidatos, respectivamente. Almeida \& Col. (2) obtiveram $5,4 \%$ de reações positivas em 786 candidatos examinados em um Banco de Sangue não esperificado de São Paulo. Realizando a R.F.C. em 178 candidatos a doadores voluntários ou habituais do Banco de Sangue do Hospital das Clínicas da F.M.U. São Paulo, Nussenzweig \& col. (31) encontraram trés reaçōes positivas $(1,7 \%)$ e sete duvidosas. Pereira da Silva \& Lima (39) realizaram uma pesquisa entre 237 candidatos não selecionados a doadores no Banco de Sangue do Recife e encontraram $8(3,6 \%)$ com R.F.C. positivas. Brofman (9), estudando a incidência da doença de Cnagas no Norte do Paraná, referiu que na Santa Casa de Misericórdia de Londrina a reação de Guerreiro-Machado foi positiva em $7 \%$ dos can- dados tanto no que diz respeito ao quadro clínico como laboratorial e parasitológico.

Pellegrino (38) de 1955 a 1958 teve a oportunidade de realizar a R.F.C. em 10.982 candidatos a doadores que se apresentaram a oito diferentes Bancos de Sangue de Belo Horizonte (Santa Casa de Misericódia - $1.253,11 \%$ de positividade; Hospital Vera Cruz - 1.869 candidatos, 7,8\% com reações positivas; Banco de Sangue São Pedro e São Paulo - 1.721 candidatos, 5,3\% de reações positivas; Hospital Felício Roxo - 3.010 candidatos, $3,9 \%$ de positividade; Hospital São Lucas - 201 candidatos, $6,7 \%$ com reações positivas; Banco de Sangue da Fac. Medicina -2.723 candidatos, $8,4 \%$ com reações positivas; Hospital S. Francisco - 164 candidatos, 5,7\% com reações positivas e Banco de Sangue da Fundação Benjamin Guimarães - 41 candidatos, $2,6 \%$ com reações positivas). Os resultados globais foram os seguintes: 
reaçōes positivas: $725 ; r$ duvidosas, $208 ; 0$ percentual de resultados positivos foi de $6,79 \%$.

Freitas \& Siqueira (20) durante o Congresso Internacional sôbre doença de Chagas realizado no Rio de Janeiro, mostraram sua experiência a respeito do tema entre doadores de sangue da cidade de Ribeirão Prêto, tomados sem seleção, encontrando os seguintes resultados: em 3.055 candidatos a doadores do Banco de Sangue do Hospital das Clínicas , 440 (14,4\%) apresentaram reações positivas e em 6.405 candidatos a doadores examinados no Banco de Sangue do Hospital São Sebastião (Santa Casa de Misericórdia), $640(10,8 \%)$ tiveram reações positivas. Jatene \& Jacomo (23) realizaram a reação de Guerreiro Machado em 640 doadores nāo selecionados do Banco de Sangue Central de Uberaba, encontraram 96 positivas e que fornece o percentual bastante elevado de $15 \%$. Mortep (27) foi o primeiro a realizar um inquérito sorológico para diagnóstico da doença de Chagas na Guanabara em 647 doadores do Banco de Sangue do Hospital dos Servidores do Estado, encontrando pequena incidência: $0,46 \%$. Já Rodrigues da Silva \& col. (41), praticando a R.F.C. com antígeno de Trypanosoma cruai pela técnica qualitativa em 435 doadores do Banco de Sangue do Hospital Escola São Francisco de Assis, no Estado da Guanabara, encontraram indice de positividade bem mais elevado $-1,83 \%$ (oito reaçōes positivas).

Mellone \& col. (26) no Banco de Sangue do Hospital das Clínicas da Fac. Medicina da Universidade de São Paulo mediante a R.F.C., encontraram $1,5 \%$ de positividace. Ferreira \& col. (18) registraram em 756 candidatos a doadores do Banco de Sangue do Instituto de Hematologia "Artur Siqueira Cavalcanti" 14 reaçōes de Guerreiro-Machado positivas $(1,83 \%)$ e duas duvidosas $(0,28 \%)$.

Amato Neto \& col. (5) relataram mais um caso indubitável de transmissão da doença de Chagas por transfusão de sangue. Carneiro (10) publica o caso de um paciente portador de anemia hemolítica auto-imune secundária a doença de Hodgkin, no qual foram encontradas formas de Trypanosoma cruzi no sangue periférico após uma das transfusões a que foi submetido. Alexandre (1) no Instituto Hemoterápico de Goiânia verificou dentre 1.474 candidatos a doadores, 162 reaçōes de Guerreiro-Machado positivas $(11 \%)$ e Oliveira \& Cesarino Neto (33), em 97 candidatos a doadores não selecionados, encontraram 25 com reações positivas $(25,8 \%)$. Coura \& col. (12, 13) e Coura (14) efetuaram no Banco de Sangue Santa Catarina, instalado no Hospital Graffrée-Guinle e no Instituto de $\mathrm{He}$ moterapia Artur Siqueira Cavalcanti, no Estado da Guanabara, 4.595 R.F.C. para o diagnóstico da doença de Chagas pela técnica de Kolmer, utilizando antígeno "Cruzi". Verificaram em 58 casos a R.F.C. positiva, o que corresponde a uma positividade de $1,26 \%$. Dos 43 doadores com R.F.C. positiva estudados clínica e laboratorialmente, apenas 9 apresentaram alterações clínicas e/ou ECG e radiológicas atribuiveis à parasitose, enquanto o xenodiagnóstico foi negativo em todos. Dos 24 pacientes que receberam transfusão de sangue de doadores com R.F.C. postiva, seis tiveram também reações positivas, um dos quais apresentou evidência de infecção aguda, com febre, e sinais de insuficiência cardíaca, aumento da área cardíaca, derrame pleural e alterações ECG (sinais de miocardite). Gonzaga \& col. (21) executando a R.F.C. para o diagnóstico da doença de Chagas no Banco de Sangue Santa Catarina (Guanabara) em 25.508 doadores, encontraram 135 reaçōes positivas $(0,52 \%)$. Lima \& col. (24) efetuaram a R.F.C. para o diagnóstico da doença de Chagas em 422 doadores do Banco de Sangue da Fac. Medicina da Univ. Federal do Ceará e em 808 doadores do Banco de Sangue da Maternidade Escola Assis Chateubriand, verificaram 14 reações positivas $(5,2 \%)$ no primeiro e $36(8,6 \%)$ no segundo.

Amato Neto \& col. (7) relataram três novos casos de doença de Chagas transmitida pela transfusão de sangue e salientaram que êsses acidentes decorreram da não observância das medidas preventivas bâsicas.

Santos \& col. (42) examinaram os sôros de 65 doadores de diversos Bancos de Sangue de Vitória do Espírito Santo, por intermédio da reação de Guerreiro-Machado, não sendo encontrados sôros reativos. A maioria dos autores que lidam com o 
problema recomendam, como medida profilática, a realização da reação de Guerreiro-Machado entre os candidatos a doadores de sangue. Essa medida, embora de grande valor, é de aplicação difícil na prática, pelas dificuldades relativas à reação em diversas oportunidades e, por outro lado, um número razoável de doadores teria de ser excluído. Por êsses motivos, Nussenzweig \& col. (29) iniciaram pesquisas experimentais no sentido de encontrarem uma substância que adicionada ao sangue "in vitro", tivesse efeito tripanosomicida, sem, no entanto, torná-lo impróprio para a transfusão. Inúmeros agentes químicos foram ensaiados e os melhores resultados foram conseguidos com corantes tri-fenil-metânicos, em particular a violeta de genciana numa concentração de ... 1:4.000, após um tempo de contacto com o sangue de 24 horas. Os autores verificaram que êste corante não apresenta atividade hemolítica, nem efeitos tóxicos apreciáveis nesta concentração. Em 46 transfusões de $500 \mathrm{ml}$ de sangue contendo $0,1 \mathrm{~g}$ da droga, não observaram quaisquer sinais ou sintomas de intolerância atribuíveis à substância. Recomendaram que, quando não fôr possível realizar-se a reação de Guerreiro-Machado (22) em candidatos a doadores suspeitos de estarem infectados pelo Trypanosoma cruzi, seja a violeta de genciana adicionada ao sangue profilàticamente, na concentração de $1: 4.000$, devendo o tempo de contacto ser no mínimo de 24 horas. Em vista dos excelentes resultados obtidos, Nussenzweig \& col. (32) adicionaram a violeta de genciana nas concentrações de 0,25 ou $0,50 \mathrm{~g}$ por litro, em frascos contendo sangue de doadores com reações de Guerreiro-Machado positivas. A transfusão efetuada em 18 pacientes não for capaz de transmitir a infecção, após cuidadosos exames parasitológicos e sorológicos. Contribuição de apreciável valor sôbre o assunto foi relatada por Amato Neto \& Melone (4). Estes autores praticaram em paciente voluntário transfusão de sangue doado por um enfêrmo com a forma aguda da doença de Chagas, após prévia adição de violeta de genciana na concentração de $0,5 \mathrm{~g}$ por litro e após permanência de 48 horas em geladeira. Durante 90 dias foi o receptor investigado no sentido de ser detectada possível transmissão da parasitose. Assim, exames clínicos sucessivos não mostraram quaisquer queixas ou alteraçōes e reiteradas pesquisas parasitológicas e sorológicas foram negativas. Rezende \& col (40) abordaram sua experiência com o uso rotineiro de violeta de genciana na concentração de 1:4.000 em mistura com o sangue, como medida profilática no Banco de Sangue Geral de Goiânia para evitarem transmissão da doença de Chagas por transfusão de sangue. Em 32 meses de funcionamento do referido Banco de sangue, foram realizadas 2.973 transfusões em $\mathbf{7 7 4}$ pacientes, não se constatando reaçōes transfusionais atribuiveis à violeta de genciana e os pacientes que foram necropsiados por causas diversas, não encontraram impregnação dos tecidos, flebites ou outras alterações ligadas diretamente ao corante. Um doente durante seis meses recebeu cêrca de $36.000 \mathrm{ml}$ de sangue, em um total de 74 transfusões. A quantidade máxima transfundida de uma só vez no mesmo paciente foi de $4.000 \mathrm{ml}$, sem que se tenha observado qualquer efeito colateral tóxico do corante. $O$ único caso de transmissão da doença de Chagas por transfusão de sangue observado naquele periodo foi o de um paciente que, por solicitação do hematologista, recebeu transfusão de sangue sem adição de violeta de genciana.

Apesar de ser uma medida profilática bastante eficiente, alguns hemoterapeutas não aceitam a introdução da violeta de genciana em adição ao sangue a ser transfundido. Para sanar esta dificuldade, Amato Neto \& col. (6), em trabalho experimental realizado em camundongos, com cêpa altamente virulenta de Trypanosoma cruzi, verificaram que $J$ plasma liofilizado dêstes animais injetado em outros animais da mesma espécies, era incapaz de transmitir a parasitose, ao contrário do grupo testemunho que recebeu plasma não submetido à técnica em questão. Julgaram os Autores que a liofilização do plasma representa recurso satisfatório para prevenir a transmissão da doença de Chagas em Bancos de Sangue.

A nossa atual investigação veio mostrar que o problema ainda é muito grave, pois o índice de positividade encontrado em doadores do Banco de Sangue do Hospital das Clínicas da F.M.U.F.Pe. é bastarıte sugestivo da possibilidade de ocorrêncıa de infecção chagásica postranfusional. 


\section{$S U M M A R Y$}

In 136 donors from the Blood Bank of the Hospital das Clinicas da F.M.U.F.Pe., Brazil, a sorological survey was carried out based on the complement fixation test for the diagnosis of Chaga's disease with Trypanosoma cruzi antigen, using qualitative technique (Muniz and Freitas, 1944). Six positive reacticns $(4,41 \%)$ were found

\section{B I B LIOGR A FI A}

1. ALEXANDRE, A. - Citado por REZENDE, J.M. \& col. (40) .

2. ALMFIDA, J.O., FREITAS, J.L.P., and BRANDÃO, M. -- Complement fixation test w:th a triple antigen for syphilis, tuberculosis, leprosy or Chagas disease in blood banks. Am. J. Trop. Med. Hyg., 3:490-494, 1954.

3. AMATO NETO, V. - Contribuição ao conhecimento da forma aguda da doença de Chagas. Tese. Fac. Medicina Univ. São Paulo, 1958.

4. AMATO NETO, V., \& MELLONE, O. - Estudo sôbre a eficácia da violeta de genciana na profilaxia da transmissão da doença de Chagas em Bancos de Sangue: investigação em voluntário, receptor de sangue de caso agudo, ao qual foi adicionado o corante. Hospital (Rio), 55:343-346, 1959.

5. AMATO NETO, V., MAGALDI, C. \& BIANCHI, A. - Comprovação de mais um caso de transmissão da doença de Chagas por transfusão de sangue. Hospital (Rio), 64:123-130, 1963.

6. AMATO NETO, V. LEONHARDT, M. \& SOUZA, H.B.W.T. - Liofilização do plasma: medida capaz de evitar a transmissão da doença de Chagas em Bancos de Sangue. Rev. Inst. Med. Trop. São Paulo, 8:122-124, 1966.

7. AMATO NETO, V., DOLES, J., RASSI, A., BORGES A.P., REZENDE. J.M. \& GOMES M.C.O. - Relato de novos casos de transmissão da doença de Chagas por transfusão de sangue. Rev. Inst. Med. Trop. São Paulo, 10: 46-51, 1968.

8. BIANCALANA, A., FREITAS, J.L.P., AMATO NETO, V., NUSSENZWEIG, V. \& SONNTAG, R. - Investigação sorológica sôbre doença de Chagas entre candidatos a doadores em Bancos de Sangue nos Estados de São Paulo e Minas Gerais. Hospital (Rio), 44:745-749, 1953.

9. BROFMAN, S. - Incidência da doença de Chagas no Norte do Paraná. Arq. Bras. Cardiol., 2:209-210, 1958.
10. CARNEIRO, R.I. - Achados anátomo-patológicos em um caso de anemia hemolitica adquirida. Rev. Goiana Med., 10:29-41, 1964.

11. CASTRO, I.M. \& UVO, D. - Incidência de moléstia de Chagas em doadores de sangue do Hospital São Luís Gonzaga, Jacanã (S.P.). Arq. Bras. Cardiol., 11:114-120, 1958.

13. COURA, J.R., NOGUEIRA, E.S. \& RODRIGUES DA SILVA. J. - O problema da doença de Chagas no Estado da Guanabara. Investigação epidemiológica em três grupos populacio lais do Estado. Hospital (Rio), 69: 999-1007, 1966.

14. COURA, J.R. - Contribuição ao Estudo da Doença de Chagas no Estado da Guanabara. Tese. Fac. Medicina Univ. Federal do Rio de Janeiro, 1966.

15. DIAS, E. - Um ensaio de profilaxia da moléstia de Chagas. Rio de Janeiro, Imprensa Nacional, 116 pp., 1945.

16. FARIA, R., MELLO, N.R. \& MURAT, L.G. - Contribuição para o estudo médico e social do doador de sangue. Folia Clínica et Biológica, 16:158168, 1950.

17. FARTA, R. - Sífilis. maleita, doenca de Chagas e transfusão. Folia Clínica et Biológica, 17:113-117, 1951.

18. FERREIRA, I.F., COURA, J.R., NOGUEIRA, E.S.. GALVÃO, F., LOPES, M.B.I. \& RODRIGUES DA SILVA, J. - Inquérito sorológico sôbre doença de Chagas em doadores de sangue do Instituto de Hematologia "Artur Siqueira Cavalcante", do Estado da Guanabara. Vida Médica, 30:6569, 1963.

19. FREITAS, J.L.P., BIANCALANA, A., AMATO NETO, "V., NUSSENZWEIG, V., SONNTAG, R. \& BARRETO, J.G. - Primeiras verificaçóes de transmissão acidental da moléstia de Chagas ao homem por transfusão de sangue. Rev. Paul. Med., 40:36-40, 1952. 
20. FREITAS, J.L.P., \& SIQUEIRA, A.F. - Prevalência da infeccão chagásica entre candidatos a doadores de sangue e outros grupos na cidade de Ribeirão Prêto, Estado de São Paulo. In Resumos do Cong. Internacional sôbre doença de Chagas, Rio de Janeiro 5 a 11 de julho de 1959, pág. 20.

21. GONZAGA, A.L., ALBERNAZ, J.A. \& ALVES. R.R. - Rotina sorológica para a doença de Chagas em Banco de Sangue. Apreciacão de resultados na Guanabara de 25.508 reaçóes de fixação do complemento. Arq. Bras. Med.. 54:289-301, 1967.

22. GUERREIRO, C. \& MACHADO, A. - Da reacão de Bordet e Gencou na moléstia de Carlos Chagas como eleme ito diagnóstico. Nota prévia. Brasil-Médico, 27:225-226, 1913.

23. JATENE, A. \& JACOMO. R. - Doenca de Chagas e transfusão de sangue. Rev. Goiana Med., 5:23-30, 1959.

24. LIMA, L.M.A., CAVALCANTE, A.B. \& ARAUJO, J.M.L. - Escudo realizado em doadores de sangue com respeito à reação de fixação do complemento para doença de Chagas. Rev. Fac. Med. Univ. Fed. Ceará, 7:3-13, 1967.

25. LUCENA, D.T. - Epidemiologia da doença de Chagas em Pernambuco. IV. - A reação de Guerreiro Machado na determinação do nivel endêmico. Rev. Brasil. Malariol. D. Trop., II: $715-720,1959$.

26. MFLLCNE, O., AMATO NETO, V. \& LCPES, A. - O problema da transm'ssão da doença de Chagas ror transfusão de sangue no Hospital das Clínicas de Sāo Paulo. Ann. Cong. Internacional sôbre doença de Chagas, 3:893-897, 1962 .

27. MORTEO, E.R. - Aspecto imunológico da doença de Chagas em doadores de sangue na Cidade do Rio de Janeiro. Tese. Farmícia e Odontologia do Estado do Rio de Janeiro, 61 pp., 1960.

28. MUNIZ, J. \& FREITAS, G. - Contribuição para o diagnóstico da doença de Chagas pela reação de imunidade. I - Estudo comparativo entre a reação de aglutinação e de fixação do complemento. Mem. Inst. Oswaldo Cruz, 41:303-333, 1944.

29. NUSSENZWEIG, V., SONNTAG, R., BIANCALANA A., FREITAS. J.L.P., AMATO NETO, V. \& KLOETZEL, J. - Ação de corantes tri-fenil-metânicos sôbre o Trynanosoma cxuzi "in vitro". Emprêgo da violeta de genciana na profilaxia da transmissão da moléstia de Chagas por transfusão re senrue. Hospital (Rio), 44: 731-744, 1953.
30. NUSSENZWEIG, V., NUSSENZWEIG, R.S., FREITAS, J.L.P., AMATO NETO. V., BIANCALANA, A. \& KLOETZEL, J. - Ação de agentes físicos e químicos sôbre o Trypanosoma cruã $i$ "in vitro". Hospital (Rio), 45:589$599,1954$.

31. NUSSENZWEIG, V., AMATO NETO, V., FREITAS, J.L.P., NUSSENZWEIG, R.S. \& BIANCALANA, A. - Moléstia de Chagas em Banco de Sangue. Rev. Hosp. Clin. Fac. Med., São Paulo, 10:265-283, 1955.

32. NUSSENZWEIG, V., AMATO NETO, V. \& MELLONE, O. - Novos dados sôbre o emprêgo da violeta de genciana na pi ofulaxa da transmıssão da doença de Chagas por transfusäo de sangue. Hospital (Rio), 55: 183-188, 1959.

33. OLIVEIRA, C. \& CESARINO NETO, J.B. - Citado por REZENDE, J.M. \& col. (40).

34. PAPROCKI, J. - Citado por PELLEGRINO, J. (36).

35. PASSALACQUA, C.S.P., AMATO NETO, V., KATZ, I. \& DAMASCO, A. - Incidência da doença de Chagas entre candidatos a doadores de um Banco de Sangue de São Paulo. Inquérito sorológico. Hospital (Rio), $43: 445-447,1933$.

36. PELLEGRINO .J. - Transmissão da doença de Chagas pela transfusão de sangue. Prime ras comprovaçōes sorológicas $\mathrm{em}$ doadores e em candidaıos a doadores de sangue. Rev. Bras. Med., 6:297-301, 1949.

37. PELLEGRINO, J.. BORROTCHIN, M., LEITE, G. \& BRENER, Z. - Inquérito sôbre a doença de Chagas em candidatos a doadores de sangue. Mem. inst. Oswaldo Cruz, 49:055$564,1951$.

38. PELLEGRINO, J. - Doença de Chagas e transfusão de sangue. Rev. Bras. Malariol. D. Trop., 2:697-706, 1959.

39. PEREIRA DA SILVA, L.M. \& LIMA, D. - Pesquisa de infecção pelo Trypanosoma cruai entre candidatos a dcadores em Banco de Sangue de Recife-Pernambuco. Publ. Médicas, 27 (n. ${ }^{\circ}$ 195) : 23-25, 1956.

40. REZENDE, J.M., ZUPELLI, W. \& BAFUTTO, M.G. - O problema da transmissão da doença de Chagas por transfusão de sangue. Emprêgo da violeta de genciana como medida profilática. Rev. Goiana Med., 2: $3 .-41+465$.

41. RODRIGUES DA SILVA, J., COURA, J.R. \& QUEIROZ, G. - Invest.gação sôbre a doença de Chagas no Estado da Guanabara. Inquérito sorológico entre doadores de sangue e doentes de ambulatório. Arq. Bras. Med., 51: 35-38, 1961. 
42. SANTOS, U.M., MURAD, V. \& RIOS, W. - Pesquisa de chagásicos em doadores de sangue em Vitória, Espírito Santo. IV Congresso Sociedade Brasileira Medicina Tropical, Recife, 18 a 21 de fevereiro de 1968 .

43. SULLIVAN, T.D. - Viability of Trypanosoma cruzi in citrated blood stored at room temperature. J. $\mathrm{Pa}$ rasitology, 30(3):200, 1944

44. WEINMAN, D. \& MCALLISTER, J. Prolonged storage of human pathogenic protozoa with conservation of virulence. Am. J. Hyg., 45:102-121. 1947. 